\title{
EDITORIAL
}

\section{PSYCHIATRY OF HIV/AIDS}

Way back in 1987, Kubler-Ross in her book entitled "AlDS, the ultimate challenge" wrote, "AlDS has become one of the largest socio-political issues, a dividing line of religious groups, a battleground for ambitious medical researchers and the biggest demonstration of man's inhumanity to man..." (1). Much of this remains true today as the acquired immune deficiency syndrome (AIDS) pandemic continues to ravage the world and the African continent in particular. Soon after the isolation of the human immune deficiency virus (HIV), psychological syndromes associated with AIDS were described (2). lnitially the emphasis was on AIDS anxiety and phobia. However it was quickly realised that the AIDS patients were prone to develop various psychiatric conditions and that these could vary as the disease progressed. The situation is further complicated by the fact that the spread of sexually transmitted diseases (including AIDS) and other related conditions such as substance use are intimately linked to human behaviour and hence to psychiatric illness as manifestations of abnormal behaviour. The World Health Organisation (WHO) also acknowledges, "Poverty as a major contributor to mental illness, stress, suicide, family disintegration and substance use" (3). In this issue of the journal some of the relationships between these variables are highlighted (4). The importance of psychiatry in this area is further underscored by the fact that although only $8 \%$ of the global burden of disease (GBD) is due to mental illnesses, $34 \%$ of the GBD is due to disorders that are behaviourally related such as HIV and substance use (5).

The neuropsychiatric sequalae of HIV infections are protean. They are considered primary if the disorder can be directly attributed to the immunopathological events related to the infection. These include the HIVrelated dementia complex and HIV associated minor cognitive/motor disorder $(6,7)$. It is estimated that about $15 \%$ of the patients develop HIV-related dementia. Among the risk factors are old age, decreased body mass, decreased haematocrit and a history of intravenous drug abuse(8). Secondary complications such as delirious states can be caused by cerebrovascular complications and the side effects of the various chemotherapeutic agents. For example aciclovir, amphotericin, didanosine and zidovudine among others may cause confusion and somnolence. Another common condition is the HIVassociated acute stress reaction. It is characterised by the sudden onset of intrusive thoughts, ruminating over the future and implications of the infection. In some cases severe disturbance in behaviour can occur resulting in rage and brief psychotic states. Generally these symptoms are short lived and subside within three days (9). The fear of having contracted AIDS, can also cause emotional problems among those who are HIV-negative.
The so-called "worried well" present with symptoms of anxiety and hypochondriasis. They may go doctorshopping and seek repeated HIV tests despite assurances that all is well.

Depression is very common among HIV infected patients (10). Apart from the psychological causes, it is thought that neuropathological changes caused by the virus in the deep grey structures alter the neurotransmitters balance leading to depression. Recognition of mild forms of depression in the debilitated patient should not be difficult if more attention is paid to the psychological symptoms (for example, hopelessness and suicidal ideation) rather than the neurovegetative symptoms such as poor appetite and weight loss. In addition to administering the antiretroviral drugs and the specific therapies to combat the opportunistic infections, the psychiatric conditions should be treated as well. For the psychotic symptoms, the atypical antipsychotics such as risperidone are the best choice, since patients with AIDS when treated with the typical antipsychotics are prone to develop tardive dyskinesia, neuroleptic malignant syndrome and severe dystonic reactions (11). The depressed patients respond well to the whole range of antidepressants, but the selective serotonin reuptake inhibitors (SSRls) are preferable (except in patients with diarrhoea) because of their safety profile. The tricyclic drugs such as imipramine and amitriptyline are also safe in HIV patients and the initial fears that they may worsen HIV related cognitive impairment or precipitate delirium have not been confirmed.

Mania in HIV-positive individuals may either be due to a chance occurrence or to the side effects of the drugs used (9). Didanosine (ddl), ganciclovir, procarbazine, estavudine ( $4 \mathrm{~T}$ ) steroids and zidovidine (AZT) have been associated with the precipitation of manic episodes. In the treatment of such cases, lithium is not advisable due to the fluid and electrolyte imbalances that are common in these patients and can lead to toxicity. The standard neuroleptics such as haloperidol and chlorpromazine may also cause problems, as indicated above, but adequate control can be achieved using the anticonvulsant medications such as carbamazepine and sodium valproate. Almost any psychiatric condition may therefore result from HIV infection but these examples illustrate how the various factors are related.

In working with patients with AIDS/HIV, as with other potentially fatal illnesses one needs to recognise the major stages of dying: denial and isolation, anger, bargaining, depression and finally acceptance. It is essential to note that it is not only the patient who goes through these stages after a diagnosis but his/her family, and even the hospital staff caring for the patient. The 
duration of each of the stages is variable and may last for years in certain individuals. Counselling is therefore essential but this should be offered judiciously just like after any traumatic event. The usefulness of counselling and debriefing sessions are increasingly being questioned, with some views that the sessions may actually prolong the maladaptive reactions (12-14). However patients who have come to terms with their status and have an optimistic outlook tend to fare better. Compliance with medical treatment is also better in highly motivated patients. Psychiatrists may therefore help the medical team by coordinating anxiety reducing strategies and suggesting appropriate psychotropic medication.

For the HIV/AIDS patient, close collaboration between the medical team and the psychiatric team is necessary. At the community level comprehensive health policies are essential. These should include other factors related to health such as reducing poverty, providing universal basic education, decent housing and adequate nutrition. In short the socio-economic status of the individuals must be improved. These are Herculean tasks and will need multidisciplinary approach. Efforts must however be made. Only then can we hope to overcome the challenges posed by the HIV scourge.

C. J. Othieno, MBChB, MMed (Psych) (Nrb), Senior Lecturer, Department of Psychiatry, Faculty of Medicine, College of Health Sciences, University of Nairobi, P.O. Box 19676, KNH-00202, Nairobi, Kenya.

\section{REFERENCES}

1. Kubler-Ross E. AIDS, The Ultimate Challenge. Macmillan, New York. 1987

2. Nichols, E.S. and Ostrow, D.G. (Eds). Psychiatric Implication of Acquired Immune Deficiency Syndrome. American
Psychiatric Press. Inc. Washington D. C. 1984.

3. World Health Organisation. Bridging the gaps. World Health Organisation. Geneva, 1995.

4. Sebit, M.B., Tombe, M., Siziya, S., Balus, S., Nkomo, SDA. and Maramba P. Prevalence of HIV/AIDS and psychiatric disorders and three related risk factors among adults in Epsworth Zimbabwe. East Afr. Med. J. 2003; 80:10.

5. Eisenberg, L. Psychiatry and health in low-income populations. In :New Oxford Textbook of Psychiatry (Eds. Gelder MG, Lopez-lbor J.J and Andreasen NC). Oxford University Press Oxford. 2000; 9-12.

6. Mc Arthur, J.C., Hoover, D.R., Bacellar, H. et al. Dementia in AIDS patients: incidence and risk factors. Neurology. 1993; 23:S34-S37.

7. Maj, M., Starace, F. and Sartorius. N. Mental disorders in HIV-1 Infection and AIDS. Hogrefe and Huber, Bern. 1993

8. Maj, M. Dementia due to HIV diseases. In :Nell oxford Texbook of Psychiatry (Eds. Gelder M.G, Lopez-lbor J.J and Andreasen- NC). Oxford University Press. 2000; 436439.

9. Ayuso-Mateos J.L. Psychiatric aspects of infections. In New Oxford Textbook of Psychiarty (Eds. Gelder MG, Lopez-lbor J.J and Andreasen N.C). Oxford University. Press. 2000; 1168-1171.

10. Maj, M. Depressive syndromes and symptoms in subjects with human immunodeficiency virus (HIV) infection. Brit. J. Psch. 1996; 169:117-122.

11. Ayuso, J.L. Use of psychotropic drugs in patients with HIV infection. Drugs. 1994; 4:599-610.

12. Chemtab, C., M., Thomas, S., Wayne, L., et al. Postdisaster psychological intervention; a field study of the impact of debriefing on psychological distress. Amer. J. Psych 1997; 154:415-417.

13. Raphael, B., Meldrum, L. and Mcfarlane A. Does debriefing after psychological trauma work? Brit. Med. J. 1995; 510:1479-1480.

14. Hobbs, M. and Diana, S. Counselling in primary care and in general hospital settings. In New Oxford Textbook of Psychiatry. (Eds. Gelder MG, Lopez-lbor J.J and Andreasen NC). Oxford University Press. 2000; 1369-1370. 